\title{
Psicologia e Religião: Possibilidades de Interação
}

\author{
Haller E. S. Schünemann
}

\section{Resumo}

O debate sobre Ciência e Religião tem sido cada vez mais sistematizado com o objetivo de superar a visão estereotipada do conflito entre ambos. Tendo em vista que a Ciência é um saber bastante diversificado, assim como a Religião. é necessário focar aspectos específicos para a construção de reflexões sobre o tema. Nesse artigo, a Psicologia é escolhida como Ciência a construir um diálogo com a Religião. A Religião, nesse artigo, é entendida tanto como um tipo de experiência, quanto como um saber sistematizado (Teologia). Procura-se mostrar que a postura de diálogo é preferível às tentativas de integração, devido às implicações tanto práticas como teóricas. Desta forma, pode-se aumentar o uso da Psicologia tendo em vista o caráter laico da maior parte das sociedades ocidentalizadas.

Palavras-chave: Psicologia - Interação Ciência e Religião - Epistemologia.

\section{Abstract}

Debate Science and Religion has been increasingly systematized in order to overcome the stereotypical view of the conflict between them. Given that 
science is a very diverse knowledge, so with religion is necessary to focus on specific aspects for the construction of thoughts on the subject. In this article, Psychology Science is chosen as building a dialogue with religion. Religion, in this article, is understood both a type of experience, as a systematized knowledge (Theology). It will be shown that the posture of dialogue is preferable to attempts at integration, due to both practical and theoretical implications. Thus, one can increase the use of Psychology in view of the secular character of most westernized societies.

Key-Words: Psychology - Interaction Science and Religion - Epistemology.

\section{Introdução}

Um dos desafios ao se tratar a respeito de Ciência e Religião é podermos oferecer contribuições precisas e importantes sobre a temática. Neste ensaio desejamos focar as possibilidades de interação entre a Psicologia e Religião e algumas implicações práticas. Para podermos discutir essa questão de forma satisfatória julgamos necessário primeiro apresentar a questão Ciência e Religião, dentro de uma perspectiva filosófica. Posto o contexto no qual Ciência e Religião podem ser pensadas, trataremos especificamente da Psicologia como Ciência. A partir da caracterização da Psicologia pretendemos discutir os possíveis modos de interação com a Ciência e quais seriam as vantagens e desvantagens de cada forma de interação. Desta forma, esperamos contribuir para profissionais das áreas interessadas refinarem as suas posições.

\section{O Desafio Conceitual}

A primeira questão que podemos pensar é por que estabelecer uma relação entre Ciência e Religião. Serão os cientistas ou os religiosos os mais interessados nessa temática? Outra questão pertinente a ser levantada é: existe alguma vantagem em estabelecer interações entre dois campos de conhecimento diferentes? Se há quem são os beneficiados, os especialistas ou a coletividade em geral? Embora essas questões sejam muito importantes, pretendemos responde-las de forma indireta. Vamos apresentar e discutir o conceito de Ciência e Religião numa breve perspectiva histórica que consideramos fundamental para contextualizar a nossa argumentação. 
Embora, como destacam Barbour ${ }^{1}$ e Harrison ${ }^{2}$, tenha se construído contemporaneamente uma visão de um conflito entre Ciência e Religião, essa abordagem do tema é tendenciosa e superficial. Na realidade, Harrison ${ }^{3}$ apresenta que os conceitos de Ciência e Religião são bastante recentes. Em relação à Ciência, ele afirma que:

a ciência, como a disciplina é correntemente entendida, emergiu somente durante o século XIX. Antes disto, estudantes da natureza se consideravam na busca de uma "filosofia da natureza" ou uma "história natural" disciplinas com uma orientação um tanto diferente daquelas da ciência do século XXI.

Em relação à Religião, ele destaca que:

Afirma-se que "religião" e o plural "religiões" não começaram a ter seus significados atuais até o século XVII. A noção de que existem "religiões", distintas por conjuntos discretos de crenças e práticas e ligadas por uma "religião" comum e genérica, é de fato um produto do Iluminismo Europeu. Durante este periodo, a necessidade aguda de chegar a algum critério para julgar entre diferentes credos levou à construção de "religiões" como conjuntos de crenças propositadas que poderiam ser imparcialmente comparadas e julgadas.

Diante do exposto por Harrison, que representa a síntese do pensamento de diversos autores a respeito de uma história da Ciência, podemos perceber que a questão que se propõe a discutir Ciência e Religião, trata de um tema, a rigor, atual. Pois só após o Iluminismo é que os saberes eruditos vão se separar em áreas distintas e com as categorias Religião, Filosofia e Ciência. Assim, a ideia de um conflito "natural" entre Ciência e Religião não corresponde ao fato. Isso não quer dizer que não seja perceptível que elas têm uma posição social hoje diferenciada. Em um número expressivo de países, não há mais religião oficial, e a maior parte, se não a totalidade dos saberes apresentados

\footnotetext{
${ }^{1}$ Cf. Barbour, Ian. Quando a Ciência encontra a Religião- Inimigas, Estranhas ou Parceiras? São Paulo, Cultrix, 2000. Cp.1.

${ }^{2}$ Cf. Harrison, Peter. The Cambrige Companion to Science and Religion. Cambride, Cambrige Univestiy Press, 2010. p.1-17.

${ }^{3}$ Cf. Harrison, Peter. "Ciência" e "Religião": Construindo os Limites. REVER- Revista de Estudos da Religião. Mar. 2007. p.1,2.
} 
nos sistemas escolares estão fundamentados em conhecimentos sustentados pela Ciência, em sua acepção atual. A maioria das políticas de saúde pública, por exemplo, é defendida em nome da Ciência, assim como boa parte das políticas educativas ou econômicas. Assim, podemos perceber uma assimetria na relação entre a Ciência e a Religião na sociedade contemporânea.

Esta assimetria pode ser interpretada de várias maneiras, nesse ensaio não pretendemos demonstrar as razões dessa dinâmica. Contudo, pensamos ser importante a consciência dessas diferenças a fim de podermos ter um quadro social para avaliarmos os modelos teóricos de interação entre a Ciência e a Religião.

Consideramos que em parte é esta assimetria de valor na sociedade atual que tem levado à discussão de repensar as formas possíveis de interação entre Ciência e Religião. Muitos admiradores da religião, tanto leigos como especialistas, têm sentido a necessidade de fugir de um clichê colocado por vários setores da sociedade moderna, que vêem como natural o antagonismo entre Ciência e Religião. Assim, supomos que aqueles que estão interessados de alguma forma no tema, estão de um modo geral buscando modelos e propostas que visam superar essa concepção superficial de um conflito "natural" entre Ciência e Religião. Não desejamos negar a existência de conflitos entre conhecimentos científicos e religiosos, mas sim, afirmar que coloca-la como "natural" e a única forma possível, é reduzir tremendamente a discussão.

Nessa proposta de sistematização da interação entre Ciência e Religião têm surgido alguns modelos. Aqui apresentamos brevemente a posição elaborada por Barbour ${ }^{4}$ para pensar o tópico em especial focando as Ciências Puras: Conflito, Independência, Diálogo e Interação. Ruse ${ }^{5}$ lembra que esse modelo tem uma importante limitação, porque envolve uma visão externa na classificação das possibilidades. Além dessa, pensamos que esse modelo não envolve uma ampla consideração de aspectos da filosofa da Ciência ou da Religião, para que possa oferecer uma visão mais rica sobre o tema. Ou seja, o modelo descrito por Barbour, embora interessante, precisa antes de ser aplicado ser investigado de forma mais problemática quanto aos conceitos de Ciência e Religião. Para um especialista em religião, delimitar adequadamente esse termo é fundamental para o desenvolvimento de seus estudos. Assim como é para o filósofo da ciência indispensável entender o que pode ser entendido como Ciência.

\footnotetext{
${ }^{4}$ Cf. Barbour, Ian, Op. Cit., cp.1.

${ }^{5} \mathrm{Cf}$. Ruse, Michael. Atheism, naturalism and science: three in one? The Cambrige Companion to Science and Religion. Cambride, CambrigeUnivestiy Press, 2010. p.229-232.
} 
A palavra Ciência, embora seja usada frequentemente no singular, supõe um conceito plural. Aqueles que trabalham na área das Ciências Humanas, por exemplo, nem sempre são vistos como cientistas. $\mathrm{Na}$ área das Ciências Humanas, observamos em especial, que ao se construir essas "novas" áreas de pesquisa, havia uma grande preocupação no final do século XIX e XX em mostrar nelas a suposta objetividade existente na Física. Esse tipo de situação descreve o que Chalmers ${ }^{6}$ coloca como a crença na Física como paradigma de Ciência. Na realidade, podemos pensar que diante do quadro da discussão da Filosofia da Ciência atual, seria mais correto falar em Ciências no sentido plural. Afinal, podemos pensar em várias formas de classificar os saberes hoje chamados de Ciências. Apenas a título de ilustração poderíamos separar em puras e aplicadas, ou naturais e humanas.

Por um lado, a discussão entre Ciência e Religião forçosamente nos impele a rejeitar qualquer concepção positivista das Ciências, como, por exemplo, a praticada por Dennett ${ }^{7}$ que a considera a única forma de conhecimento válida. Por outro lado, as posições como a de Feyerabend ${ }^{8}$ que nega qualquer característica distintiva da Ciência, também não acrescentaria nada, pois se não houve nada melhor no conhecimento das Ciências, então não há razão de investir tempo em estabelecer algum tipo de interação, é melhor simplesmente rejeitar o conhecimento científico. Diante, desses extremos colocados, precisamos esclarecer qual é o conceito de Ciências que trabalhamos para que possamos articular com clareza as propostas que desejamos apresentar entre a Psicologia e a Religião.

Primeiramente, destacamos as contribuições de Fourez ${ }^{9}$ que defende as Ciências como um conjunto de conhecimentos construídos histórica e socialmente. Essa idéia, porém, deve ser entendida com cautela. O fato de um conhecimento ser construído dentro de contextos históricos e sociais não impossibilidade de elaboração de verdades, ainda que parciais, na medida em que o avançar do tempo em função das transformações poderá levar a rever alguns conceitos tidos como verdades. Isso não quer dizer que essa limitação epistemológica elimine a capacidade de elaborar boas respostas para problemas ou explicações do mundo.

\footnotetext{
${ }^{6}$ Cf. Chalmers, Alan. A Fabricação da Ciência. São Paulo, UNESP, 1994. p.34-37.

${ }^{7}$ Cf. Dennetr, Daniel. A Perigosa Ideia de Darwin. São Paulo, Rocco, 2010; ideia apresentada ao longo da obra.

${ }^{8}$ Cf. Feyerabend. Paul. Contra o Método. Rio, Francisco Alves, 1977; esse é o tema central da sua obra.

${ }^{9}$ Cf. Fourez, Gerard. A Construção das Ciências- Introdução a Filosofia e a Ética das Ciências. São Paulo, 2008. p.227-261.
} 
Próxima a esse conceito, temos ainda a contribuição de Chalmers ${ }^{10}$ que, em uma abordagem similar, procura lembrar que o conhecimento científico é elaborado a partir de recursos extras dos cientistas, por exemplo, seus instrumentos de laboratório, e é feito a partir da observação de situações naturais ou mesmo sociais, na qual o cientista não pode forçar e escolher todos os dados que ele obterá. Assim, mesmo diante de limitantes sociais existentes na produção das Ciências, isso não quer dizer que as verdades das Ciências sejam apenas frutos dos interesses dos cientistas. As Ciências - ao lidarem com fatos e situações observáveis por muitos e passíveis de discussão de cientistas com diferentes vieses - fortalecem a busca de resultados que realmente contribuem na apreensão da realidade e numa compreensão verdadeira da mesma. Posta uma definição de Ciências, tanto em seu referencial teórico, quanto em sua diversidade, consideramos necessário agora discutir o conceito de Religião.

O termo Religião em nosso entender é equívoco e amplo. O problema de ser equívoco é por que é usado para sentidos tanto coloquiais como técnicos, nos quais nem sempre se delimita enquanto uma crença do sujeito, uma prática, um sistema de crenças ou mesmo uma atitude ou sentimento diante do inexplicável. Pensamos que Religião é um termo amplo, por que, como conceito elaborado a partir do Iluminismo, como posto por Harrison ${ }^{11}$,ele engloba objetos tão distintos quanto complexos, como Cristianismo, Budismo, Islamismo, até práticas rituais nativas, que podem ser desde cultos afro-brasileiros a cultos indígenas, ou a veneração dos antepassados. Além disso, nenhuma das grandes religiões mundiais são sistemas sem enormes divisões sobre a interpretação das crenças e práticas religiosas daquele universo. Assim, quando colocamos todos esses sistemas de crenças e práticas sob a categoria Religião estamos forçosamente dizendo que há um elemento comum em todos eles e isso permite que sejam colocados lado a lado, mas que não permitam, por exemplo, que o marxismo possa ser incluído nessa categoria.

A diversidade de Religião não é um detalhe para se pensar a questão das possíveis interações entre Ciência-Religião. Em uma coletânea organizada por Peters e Bennett ${ }^{12}$, Payne ${ }^{13}$ falando do budismo, diz que essa questão

${ }^{10}$ Cf.Chalmers, Alan. Op.cit.p.129-161.

${ }^{11}$ Cf. Harrison, Peter. "Ciência" e "Religião": Construindo os Limites. REVER- Revista de Estudos da Religião. Mar. 2007 p.11-17.

${ }^{12}$ Cf. Peters, Ted e Bennett, Gaymon. (org). Construindo pontes entre a Ciência e a Religião. São Paulo, UNESP, Loyola 2003. Essa observação inclui a própria proposta do livro.

${ }^{13}$ Cf. PAyne, Richard K. O Budismo e as ciências: pano de fundo histórico, desenvolvimento contemporâneos. In,Peters, Ted e Bennett, Gaymon. org. Construindo pontes entre a Ciência e 
raramente foi pensada como "discursos sobre religião e ciência", além do que é perceptível, que boa parte das questões propostas foram pensada a partir de uma visão teísta de religião. Realmente ao analisarmos a maior parte das questões apresentadas em Peters e Bennett ${ }^{14}$, Barbour ${ }^{15}$, Harrison ${ }^{16}$, somos levados a dizer que o debate Ciência-Religião está muito vinculado a uma associação implícita e ao mesmo tempo equívoca entre Religião e Cristianismo.

Outro aspecto problemático do termo Religião é que, na realidade, quando se propõe um diálogo entre Ciência e Religião, nos parece que fosse mais adequado chamar Ciência e Teologia. Em que pese o fato de a Teologia estar muito ligada ao Cristianismo, pensamos que sendo a Ciência um saber organizado e sistemático, o contraponto no qual deve ser estabelecido o diálogo, é com outro tipo de saber, também organizado e sistemático, que é a Teologia. No entanto, devido ao costume já consagrado, manteremos o termo Religião, mas pensando em um sentido estrito de um conhecimento sistematizado, que a rigor, deveria ser pensando como Teologia.

Diante do exposto acima, queremos então esclarecer o contexto específico da discussão desse ensaio. Por um lado, a Psicologia é escolhida, como uma das Ciências a ser pensada na reflexão entre Ciência e Religião. Por outro lado, não pensamos em uma Religião, mas em todas, isso é, religiões, para propor a discussão. Consideramos que no desenvolvimento dos argumentos a nossa opção ficará clara.

\section{Analisando a Psicologia em relação à religião}

Um dos maiores desafios para se pensar a Psicologia, é que ela é uma ciência ainda sem um corpo teórico totalmente unificado. As escolas da Psicologia como são chamadas as diferentes abordagens teóricas aos problemas do estudo do ser humano ainda se mostram como barreiras para a existência de um corpo unificado. $\mathrm{O}$ avanço do conhecimento psicológico tem demonstrado algumas possibilidades de interação entre as diversas escolas, não pensadas anteriormente. Contudo, ainda a Psicologia apresenta pelo menos três

a Religião. São Paulo, UNESP, Loyola 2003. p. 197-198.

${ }^{14}$ Cf. Peters, Ted e Bennett, Gaymon. (org). op.cit.

${ }^{15}$ Cf. Barbour, Ian. Quando a Ciência encontra a Religião- Inimigas, Estranhas ou Parceiras? São Paulo, Cultrix, 2000. Esta afirmação pode ser observada ao longo de sua obra a partir dos casos discutidos.

${ }^{16}$ Cf. Harrison, Peter. "Ciência" e "Religião": Construindo os Limites. REVER- Revista de Estudos da Religião. Mar. 2007 p.1-33. 
grandes modelos para a pesquisa: comportamentalista-cognitivista, de forte viés experimental; psicanalítica, com forte viés em processos inconscientes e justificados a partir da interpretação clínica; e a humanista, influenciada por correntes filosóficas. Ora, esse dado nos apresenta um desafio, que seria se a Psicologia não é uma ciência completamente unificada, a partir de qual referencial se pode construir uma interação com as religiões.

Outro aspecto que precisamos destacar é termos na Psicologia uma área de investigação a respeito da Religião ou das manifestações religiosas. Isso demonstra que a Religião é um tema de interesse para os psicólogos, aspecto comum às outras Ciências Humanas. Interessar-se sobre as manifestações religiosas ou investigar como as crenças religiosas afetam os comportamentos, os sentimentos, ou os processos cognitivos, é sem dúvida um tipo de interação, mas provavelmente não é o tipo esperado por aqueles que desejam estabelecer um tipo de interação com a Religião, lembrando que a definimos no contexto desse ensaio, como um corpo sistemático de crenças.

Ainda, podemos constatar em termos práticos que nem sempre a relação entre psicólogos e sacerdotes é uma relação amistosa. Como é sabido, em uma perspectiva histórica, a Psicanálise não apenas pretendeu estudar a Religião, como desqualificar sua importância para o bem-estar do indivíduo. Contudo, seria incorreto afirmar que a Psicologia em si é contrária à religião, embora possamos identificar dentro da Psicologia, escolas hostis à temática religiosa.

Como dissemos ao discutirmos a relação entre Psicologia e Religião, precisamos destacar que não deve isso ser confundido com a Psicologia da Religião. Esta deve ser entendida como uma área na qual devido à presença da religião na vida dos seres humanos, o tema em si é um objeto de estudo para a Psicologia. Nesse caso, são estudadas as crenças, a conversão, as práticas religiosas, ou mesmo a influência da religião na vida do sujeito em termos de convicção política, cuidados com a saúde, relação de gêneros, apenas para enumerar um grande número de temas estudados pela Psicologia da Religião.

Uma vez diferenciada a Psicologia da Religião de Psicologia e Religião, propomos pensar as possibilidades de interação entre os dois campos de conhecimento. Para construirmos um roteiro que possa nos auxiliar à compreensão do tema em suas implicações, tomaremos o modelo proposto por Barbour a respeito das possíveis interações entre Ciência e Religião, mesmo considerando que ele apresenta limitações. Apesar de o modelo de Barbour ${ }^{17}$

${ }^{17}$ Cf. Barbour, Ian. op.cit. cp1. 
propor quatro possíveis relações, penso que é desnecessário discutir o conflito entre Psicologia e Religião, pois em certo sentido, ele é não interação. Ele representa a impossibilidade de reconhecimento mútuo. Esse conflito deve ser lembrado apenas que ele existe tanto para religiosos, como, por exemplo, um fundamentalismo bíblico, que rejeita toda a Psicologia e considera a Bíblia como um guia completo para a saúde mental e cura de todos os problemas comportamentais; quanto para um segmento da própria Psicologia que vê na religião a fonte de todos os conflitos e culpa. Assim, consideramos não ser importante gastarmos tempo ao avaliarmos essa não interação, uma vez que aqui desejamos avaliar se é possível estabelecer interações e quais são as vantagens e desvantagens que cada modelo nos oferece. E como afirma Barbour, a idéia de Conflito sustenta-se pelo fato que "alegam que a ciência e a religião têm verdades literais e reais e as afirmam sobre o mesmo domínio, de modo que é preciso escolher uma delas".

Assim, o primeiro modelo a ser pensado efetivamente é o da Independência. Para Barbour, ${ }^{18}$ esse modelo "mantém as duas áreas em comportamentos estanques. É possível discriminá-las de acordo com as perguntas que fazem, com os domínios a que se referem e com os métodos que empregam". Uma diferença seria por que cada área tem uma metodologia diferente e trata de aspectos diferentes. Ao pensarmos especificamente na relação entre Psicologia e Religião, podemos perceber que em ambas temos um objeto em comum de reflexão que é o ser humano. Evidentemente, a metodologia para estudar esse ser humano é diferente, mas nesse caso, há aspectos em comum do próprio objeto a ser estudado. A diferença metodológica é em grande parte resultado de uma visão diferenciada do ser humano. É difícil pensar que os livros sagrados, ou mesmo os curandeiros não possuem um significativo e importante conhecimento a respeito do comportamento humano.

Consideramos que esse modelo oferece uma posição bastante cômoda e também útil. Não temos dúvida que esse modelo não significa ausência de eventuais conflitos entre a interpretação da Psicologia e uma possível interpretação da Religião. Evidentemente, nesse caso, a solução é obtida pela escolha de qual tem maior competência para responder ao tema específico do conflito. Em situações sem conflitos, os discursos poderão funcionar em paralelo sem produzir grandes tensões.

${ }^{18}$ Cf. Idem. p. 32. 
O modelo para Independência é muito positivo, quando pensamos que vivemos em uma sociedade de especialistas. Como Giddens ${ }^{19}$, ao analisar a sociedade contemporânea, destaca, hoje vivemos em um grau elevado de especialidades, no qual muitas vezes não há sequer um consenso entre especialistas de áreas diferentes. Se pensarmos, apenas a título de ilustração, o próprio saber psicológico, ainda está fragmentado em escolas, que ainda possuem visões conflitantes entre si. Assim, a existência de um eventual conflito entre a "Psicologia e Religião", com certeza, não seria um motivo para não adotá-lo. Justamente, por vivermos em uma era de especialidades, a Independência pode ser uma forma relevante de que cada especialista permaneça no seu domínio. Isso é importante, não apenas no sentido de assegurar um privilégio, mas porque justamente, diante da limitação das outras áreas, opinar sobre elas pode ser um grande risco. Imaginemos um sacerdote, sem treinamento psicológico, será que ele poderá avaliar corretamente quadros de doenças mentais? Ou imaginemos um psicólogo, sem nenhuma formação ou conhecimento religioso, será que ele poderá avaliar corretamente o sentido espiritual ou o conforto trazido pela crença religiosa? Quando falamos em avaliar corretamente não é no sentido de aceitar, mas quanto ele pode "intervir" a partir do conhecimento que ele tem na outra especialidade? Assim, não é sem razão que podemos pensar que um grande número de profissionais e mesmo de sujeitos não especialistas adotam essa visão.

Evidentemente, muitos consideram essa posição insuficiente. $\mathrm{O}$ ideal de muitos tem sido integrar a Psicologia e a Religião. Um motivo muito grande para isso é o fato de que o ser humano ser o sujeito comum de estudo nas duas áreas de saberes. Vamos avaliar a Integração. A integração entre a Psicologia e Religião é representada pelo desejo de oferecer um campo unificado de conhecimento. Dentro dessa proposta, as diferenças metodológicas, entre os dois campos de conhecimento, são minimizadas, e há uma significativa esperança de uma vez que os dois saberes focam os seres humanos, possam oferecer o máximo de integração.

Ora, como podemos integrar a Psicologia com a Religião, se como discutimos anteriormente, o sentido da palavra Religião é plural? Na realidade, o que iremos obter, é na realidade não uma unificação, mas uma fragmentação. De fato, ao investigarmos o assunto, pudemos encontrar em sítios eletrônicos propostas a respeito de Psicologia Cristã, Psicologia Espírita, Psicologia

\footnotetext{
${ }^{19}$ Cf Giddens, Anthony. As Consequências da Modernidade. São Paulo, UNESP,1991; p.83-113.
} 
Budista, como exemplos. A nossa análise dessas informações não foi suficientemente detalhista para poder fazer generalizações, mas é possível observar, nessas tentativas de integração, pelo menos duas formas de abordagem. Uma apresenta uma íntima relação entre a doutrina religiosa específica e sua correlação com a psicologia. A outra é o uso da Psicologia como um "enriquecimento" na religião. Interessante que Berger ${ }^{20}$, em sua análise das religiões nos Estados Unidos, detectava esse tipo de "integração", na qual várias igrejas passam a usar não apenas um linguajar de inspiração psicológica, mas mudam até abordagens nos momentos de culto, que se aproximam das propostas da psicologia. Se pensarmos que a integração envolve uma fusão, pensamos que isso seria começar com o conhecimento religioso e psicológico em condições de igualdade para elaborar uma compreensão do ser humano. Esse desafio teórico, embora possa parecer muito enriquecedor, acabará produzindo um conhecimento fragmentado. Afinal, como já destacamos, a religião é um saber dividido e, por tanto, a fusão da psicologia com a religião acabará produzindo uma maior fragmentação no conhecimento psicológico. Aqui vemos um significativo problema. A Psicologia, a partir de sua fundamentação teórica, desenvolve aquilo que chamamos psicoterapia. Se eu particularizo a psicologia dentro de um segmento religioso específico, teremos a produção de uma psicoterapia aplicável apenas àquele grupo de crentes. Pensamos que muitos cristãos se sentiriam desconfortáveis se soubessem que a psicoterapia que lhe é oferecida, foi desenvolvida a partir de uma visão islâmica de mundo, por exemplo. Ora, um dos mais importantes aspectos do estudo das Ciências é de alguma forma poder produzir um conhecimento aplicável em várias situações.

Ainda quanto à problemática da integração, pensamos que temos a eliminação de um campo "alternativo". Achamos interessante destacar uma ampla revisão efetuada por Dalgalarrondo ${ }^{21}$ a respeito da contribuição da religião para a saúde dos praticantes. É importante lembrar que esses estudos são dentro do que chamamos de Psicologia da Religião, mas o perfil obtido nesses estudos apresenta um dado interesse. Eles apontam que, de um modo geral, a crença religiosa agia favoravelmente para o bem-estar individual, mas era possível observar que, em especial em pessoas que adotavam crenças

\footnotetext{
${ }^{20}$ Cf Berger, Peter. O Dossel Sagrado - Elementos para uma teoria Sociológica da Religião. São Paulo, Paulus, 1985. Conceito apresentado é uma conseqüência do mercado religioso exposto por esse autor.

${ }^{21}$ Cf Dalgalarrondo, Paulo. Religião, Psicopatologia e Saúde Mental. Porto Alegre, Artmed, 2008. p.190-191.
} 
religiosas em grande oposição à cultura dominante, a religião agia de forma inversa. Além desse interessante resultado poderíamos sem dúvida relacionar que muitas pessoas tiveram conflitos de origem religiosa, e apenas uma psicoterapia secularizada deu resultados. Pensamos que caberia, também, dizer que várias pessoas reconhecem que o seu bem-estar e cura ocorreu após uma experiência religiosa, ou mesmo valendo-se dos recursos religiosos, e alcançaram resultados que não foram obtidos em uma psicoterapia. Nesse sentido, pensamos que uma proposta de integração dos dois saberes elimina um espaço alternativo. Não acreditamos, devido às próprias limitações do conhecimento humano, que uma fusão possibilitaria mais resolução de problemas, do que a Psicologia e as Religiões funcionando separadamente ou em diálogo.

Precisamos ainda apresentar o modelo de diálogo entre as duas áreas. Para Barbour $^{22}$ o modelo de diálogo envolve a possibilidade de aproximações, reconhecimento de semelhanças, mas mantendo as diferenças de forma clara. Para ele o diálogo enfatiza as semelhanças entre pressupostos, métodos e conceitos. Se aplicarmos esse a Psicologia e Religião, estamos afirmando que Psicologia e Religião mesmo sendo saberes independentes, podem estabelecer alguns diálogos. Nesse sentido, pensamos primeiramente que a Religião, e daí, qualquer religião, pode ser útil à Psicologia. Uma possibilidade dessa contribuição está no reconhecimento de que as Religiões guardam dentro de si uma visão de ser humano e uma forma de intervir nesse ser humano, que pode servir como uma fonte heurística para o psicólogo. A outra é identificar quais práticas propostas pela religião são úteis para as buscas que são feitas. Por outro lado, as religiões também podem ganhar ao entenderem o que a Psicologia tem estudado a respeito do ser humano, para enriquecimento de sua prática "pastoral". Não queremos aqui sugerir uma psicologização da religião. A partir de um viés sociológico nos atreveríamos a dizer que esse elemento empobrece as instituições religiosas, na medida em que outras instituições poderão oferecer respostas psicológicas, sem as contrapartidas muitas vezes solicitadas pelas instituições sociológicas.

\section{Considerações Finais}

Acreditamos que pudemos demonstrar que de um modo geral o Diálogo é a melhor posição. As propostas de integração, nascidas a maior parte dentro de universos religiosos, esquecem a diversidade de crenças e as limitações ainda

\footnotetext{
${ }^{22}$ Cf BArbour, Ian. op.cit. cp1.
} 
no estudo do ser humano. A própria Psicologia ainda está construindo um corpo de saber mais integrado de uma perspectiva científica. Na medida em que certos paradigmas positivistas começam a ser enfraquecidos, e as possibilidades de pesquisas cada vez mais integradas começam a prosperar, é possível emergir um conceito mais unificado do ser humano. O grande problema que poderá surgir é tomá-lo como parâmetro para detectar quais seriam as religiões válidas, pela possibilidade de integração total. Assim, pensamos que embora o Iluminismo possa ter cometido exagero na sua crítica à Religião, o fato de a esfera religiosa ter sido levada para a vida privada não parece ter diminuído em várias partes do mundo a sua relevância pessoal. Assim, se a Psicologia enquanto conhecimento público dialoga com a religião na esfera privada, em um "clima" de respeito ao diferente, podemos enriquecer o uso da Psicologia na solução dos problemas humanos.

\section{Referências Bibliográficas}

BArbour, Ian. Quando a Ciência encontra a Religião- Inimigas, Estranhas ou Parceiras? São Paulo, Cultrix, 2000.

Berger, Peter. O Dossel Sagrado - Elementos para uma teoria Sociológica da Religião. São Paulo, Paulus, 1985.

Chalmers, Alan. A Fabricação da Ciência. São Paulo, UNESP, 1994.

Dalgalarrondo, Paulo. Religião, Psicopatologia e Saúde Mental. Porto Alegre, Artmed, 2008.

Dennett, Daniel. A Perigosa Ideia de Darwin. São Paulo, Rocco, 2010.

Feyerabend. Paul. Contra o Método. Rio, Francisco Alves, 1977.

Fourez, Gerard. A Construção das Ciências- Introdução a Filosofia e a Ética das Ciências. São Paulo, 2008.

Giddens, Anthony. As Consequências da Modernidade. São Paulo, UNESP, 1991.

Harrison, Peter. "Ciência" e "Religião": Construindo os Limites. REVERRevista de Estudos da Religião. Mar. 2007. p.1-33.

.The Cambridge Companion to Science and Religion. Cambridge, Cambridge University Press, 2010. 
PAyne, Richard K. O Budismo e as ciências: pano de fundo histoiro, desenvolvimento contemporâneos. In,Peters, Ted e Bennett, Gaymon. (org). Construindo pontes entre a Ciência e a Religião. São Paulo, UNESP, Loyola 2003.

Peters, Ted e Bennett, Gaymon.(org). Construindo pontes entre a Ciência e a Religião. São Paulo, UNESP, Loyola 2003.

Ruse, Michael. Atheism, naturalism and science: three in one? In. Harrison, Peter (ed).The Cambridge Companion to Science and Religion. Cambridge, Cambridge University Press, 2010.

Haller E. S. Schünemann

Doutor em Ciências Sociais e Religião pela UMESP - Universidade Metodista de São Paulo Professor Titular do UNASP - Centro Universitário Adventista de São Paulo, nos cursos de Psicologia e licenciaturas E-mail: haller_schunemann@yahoo.com.br

Recebido em 30/11/2012 Aprovado em 23/12/2012 